Journal of Zhejiang University-SCIENCE A (Applied Physics \& Engineering)

ISSN 1673-565X (Print); ISSN 1862-1775 (Online)

www.jzus.zju.edu.cn; www.springerlink.com

E-mail: jzus@zju.edu.cn

\title{
Erratum:
}

\section{Erratum to: Quantification of the influence of rolling stock failures on track deterioration}

\author{
Yun-guang YE ${ }^{1}$, Da-chuan $\mathrm{SHI}^{\dagger 1}$, Sara POVEDA-REYES ${ }^{2}$, Markus HECHT ${ }^{1}$ \\ ${ }^{1}$ Institute of Land and Sea Transport Systems, Technical University of Berlin, Berlin 10587, Germany \\ ${ }^{2}$ AITEC, Parque Tecnológico, Valencia 46980, Spain \\ †E-mail: dachuan.shi@tu-berlin.de
}

https://doi.org/10.1631/jzus.A20e0033

Erratum to: J Zhejiang Univ-Sci A (Appl Phys \& Eng) 2020 21(10):783-798

https://doi.org/10.1631/jzus.A2000033

The original version of this article unfortunately contained a mistake.

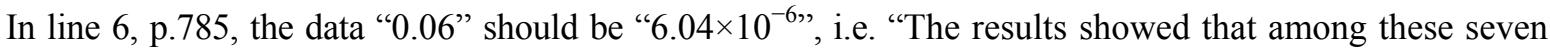
failures, the occurrence probabilities of the wheel out-of-round and the wheel flat are the highest, both are approximately $6.04 \times 10^{-6}$." 